\title{
Effect of Different Initial Light Intensity by the Soft-Start Photoactivation on the Bond Strength and Knoop Hardness of a Dental Composite
}

\author{
Eduardo DALL'MAGRO \\ Mário Alexandre Coelho SINHORETI \\ Américo Bortolazzo CORRER \\ Lourenço CORRER-SOBRINHO \\ Simonides CONSANI \\ Regina Maria PUPPIN-RONTANI
}

School of Dentistry of Piracicaba, State University of Campinas, Piracicaba, SP, Brazil

\begin{abstract}
This study evaluated the bond strength (push-out method) and Knoop hardness of Z250 composite resin, photoactivated with XL 2500 curing unit, using different protocols: continuous mode $\left(700 \mathrm{~mW} / \mathrm{cm}^{2}\right.$ for $\left.20 \mathrm{~s}\right)(\mathrm{CO})$; soft-start $\left(50 \mathrm{~mW} / \mathrm{cm}^{2}\right.$ for $5 \mathrm{~s}$, followed by $700 \mathrm{~mW} / \mathrm{cm}^{2}$ for $\left.15 \mathrm{~s}\right)(\mathrm{SS} 1)$; soft-start $\left(100 \mathrm{~mW} / \mathrm{cm}^{2}\right.$ for $5 \mathrm{~s}$, followed by $700 \mathrm{~mW} / \mathrm{cm}^{2}$ for $\left.15 \mathrm{~s}\right)(\mathrm{SS} 2)$; soft-start $\left(150 \mathrm{~mW} / \mathrm{cm}^{2}\right.$ for 5 $\mathrm{s}$, followed by $700 \mathrm{~mW} / \mathrm{cm}^{2}$ for $\left.15 \mathrm{~s}\right)(\mathrm{SS} 3)$; soft-start $\left(200 \mathrm{~mW} / \mathrm{cm}^{2}\right.$ for $5 \mathrm{~s}$, followed by $700 \mathrm{~mW} / \mathrm{cm}^{2}$ for $\left.15 \mathrm{~s}\right)$ (SS4); soft-start (250mW/ $\mathrm{cm}^{2}$ for $5 \mathrm{~s}$, followed by $700 \mathrm{~mW} / \mathrm{cm}^{2}$ for $\left.15 \mathrm{~s}\right)$ (SS5); soft-start $\left(300 \mathrm{~mW} / \mathrm{cm}^{2}\right.$ for $5 \mathrm{~s}$, followed by $700 \mathrm{~mW} / \mathrm{cm}^{2}$ for $15 \mathrm{~s}$ ) (SS6). For the push-out test, the specimens were tested in a universal testing machine at a crosshead speed of $0.5 \mathrm{~mm} / \mathrm{min}$. For the hardness test, the specimens were polished for the hardness measurements, using a $50 \mathrm{~g}$ load for $15 \mathrm{~s}$. Data were submitted to ANOVA and Tukey's test $(\alpha=5 \%)$. The results of bond strength showed that the SS3 group obtained the highest bond strength when compared to the CO group. There were no significant differences among the other modes in relation to the other groups. Regarding the other results in hardness, there were no significant differences among the groups in the surface region and up to $4 \mathrm{~mm}$ depth.
\end{abstract}

Key Words: dental composite, bond strength, Knoop hardness, soft-start.

\section{INTRODUCTION}

Composite resins are the most widely used direct restorative dental materials. Current dental composites are expected to have optical and mechanical properties comparable to those of tooth enamel and dentin and provide a service life of 10 years or more. However, the polymerization shrinkage still remains the main problem of dental composites. Regardless of composite resin formulation, polymerization shrinkage occurs due to covalent bond between monomer molecules, leading to polymeric chain shortening (1). Walls et al. (2) reported that polymerization shrinkage is influenced by the molecular weight of monomer, the filler content, the degree of conversion and the monomer formulation.
This creates contraction stress, leading to marginal gap, invasion of oral fluids and bacteria, determining the composite longevity (1). However, several factors limit the performance of this material, especially depth of cure and degree of conversion (DC). Light of an appropriate wavelength initiates polymerization of methacrylate groups producing a highly cross-linked polymer matrix. Light from the curing source must be able to adequately polymerize deeper composite regions than just the top, irradiated surface. However, as light passes through the composite, it is absorbed and scattered, reducing its effectiveness to initiate polymerization, and consequently resulting in variation of the cure with depth (3). Although high irradiance provides higher DC values, it also produces greater polymerization 
shrinkage, which may cause gap formation and further microleakage, compromising the longevity of the restoration. Another problem is that the insufficient polymerization with high residual monomers. The amount of residual monomers depends on the light source and the photoactivation method (4). This monomer may be released within the first days in oral conditions. The unreacted monomers result in inferior physical properties, and can be leached of polymeric matrix (5). Marginal integrity can be increased by absorbing stress materials under restorative materials; adhesive systems with high bond strength to tooth structure, incremental technique filling, and flowing control by light modulation during photoactivation (6).

Several methods of light modulation have been used for the photoactivation of composites with the objective of minimizing the stress generated by the polymerization shrinkage. These photoactivation methods have been suggested to initiate the composite cure reactions, maintaining DC values similar to that found using high light intensity, whilst reducing the polymerization shrinkage (7). Soft-start polymerization adopts an initially low irradiance followed by a final cure with high irradiance. A slower rate of conversion allows for better flow of the material, which in turn decreases contraction stresses, leading to better marginal adaptation. The complement of photoactivation with high irradiance is used for the composite to achieve the maximum degree of conversion (6). Irradiance diminishes as the curing tip is moved away from composite restorative material, and can be used for two-step photoactivation methods. Furthermore, the viscoelastic nature of the polymerizing composite must also be considered. During polymerization there is an irreversible increase in the elastic modulus of the composite. The moment when the loss of the flowing capacity of the material occurs is called gel-point. Prior to the gelpoint, polymerization contraction will not create stress at the restoration margins or within the material, as it is compensated by flow. However, rigid contraction after the gel-point has received much attention and has been responsible for the induction of stress at the bonding interface (8). Kinomoto et al. (9) demonstrated that the speed of the polymerization reaction has a great effect on the generation of stress. The ideal photoactivation method is primordial to optimal marginal adaptation, mechanical properties and depth of cure of composite resin (10). By using a lower irradiance, free radical formation will be lower than when a higher irradiance is used. A lower free radicals formation means that linear polymerization will initially occur to a greater extent, thus the propagating chain comes close to an adjacent free radical or initiated chain as cross-linkage can occur. This study evaluated the ideal initial irradiance using soft-start photoactivation methods to produce the highest bond strength (push-out test) and Knoop hardness for a composite resin.

\section{MATERIAL AND METHODS}

For this study, Z250 composite resin (shade A3) was used (3M/ESPE, St. Paul, MN, USA).

\section{Push-out test}

Seventy round metallic matrices ( $3 \mathrm{~mm}$ height) with a round cavity with $6 \mathrm{~mm}$ in the lower diameter and $9 \mathrm{~mm}$ in the upper diameter were used (Fig. 1).

These matrices were internally sandblasted with 40- $\mu \mathrm{m}$ aluminum oxide using a micro-etcher (Danville Eng. Inc., San Ramon, CA, USA). After sandblasting, the matrices were etched with $37 \%$ phosphoric acid for $15 \mathrm{~s}$, rinsed and dried. The silane bonding agent (Ceramic Primer) was applied and dried for $5 \mathrm{~s}$. The adhesive system (Single Bond, 3M/ESPE) was applied, air-dried for $20 \mathrm{~s}$ and photoactivated for $10 \mathrm{~s}$.

During the application of composite resin, the matrices were set on a Mylar strip positioned on a glass slab. Z250 composite resin was bulk inserted and a Mylar strip was seated on the specimen surface and manually pressed using a microscope slab to remove composite excesses.

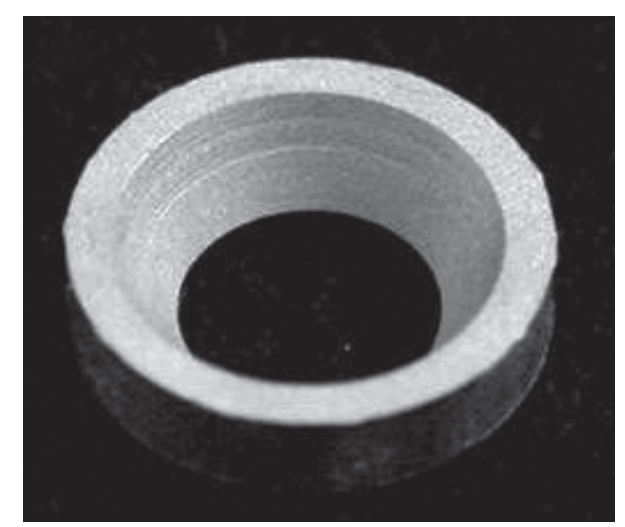

Figure 1. Matrix used for push-out test. 
The material was light cured with a halogen lamp XL2500 (3M/ESPE). The maximum irradiance checked with a radiometer (Demetron Research Corp., Danbury, CT, USA), was $700 \mathrm{~mW} / \mathrm{cm}^{2}$. Composite resin were photoactivated according to the following methods: continuous mode $\left(700 \mathrm{~mW} / \mathrm{cm}^{2}\right.$ for $\left.20 \mathrm{~s}\right)(\mathrm{CO})$; softstart $\left(50 \mathrm{~mW} / \mathrm{cm}^{2}\right.$ for $5 \mathrm{~s}$, followed by $700 \mathrm{~mW} / \mathrm{cm}^{2}$ for $15 \mathrm{~s})(\mathrm{SS} 1)$; soft-start $\left(100 \mathrm{~mW} / \mathrm{cm}^{2}\right.$ for $5 \mathrm{~s}$, followed by $700 \mathrm{~mW} / \mathrm{cm}^{2}$ for $\left.15 \mathrm{~s}\right)(\mathrm{SS} 2)$; soft-start $(150 \mathrm{~mW} /$ $\mathrm{cm}^{2}$ for $5 \mathrm{~s}$, followed by $700 \mathrm{~mW} / \mathrm{cm}^{2}$ for $\left.15 \mathrm{~s}\right)(\mathrm{SS} 3)$; soft-start $\left(200 \mathrm{~mW} / \mathrm{cm}^{2}\right.$ for $5 \mathrm{~s}$, followed by $700 \mathrm{~mW} /$ $\mathrm{cm}^{2}$ for $\left.15 \mathrm{~s}\right)(\mathrm{SS} 4)$; soft-start $\left(250 \mathrm{~mW} / \mathrm{cm}^{2}\right.$ for $5 \mathrm{~s}$, followed by $700 \mathrm{~mW} / \mathrm{cm}^{2}$ for $15 \mathrm{~s}$ ) (SS5); soft-start ( $300 \mathrm{~mW} / \mathrm{cm}^{2}$ for $5 \mathrm{~s}$, followed by $700 \mathrm{~mW} / \mathrm{cm}^{2}$ for 15 s) (SS6). For reduced irradiances, the tip of curing units was moved away from composite surface. To standardize the photo-activation distance, self-cure acrylic resin spacers (JET; Artigos Odontológicos Clássico, São Paulo, SP, Brazil) were made with $0.5 \mathrm{~cm}, 0.8 \mathrm{~cm}$, $1.5 \mathrm{~cm}, 2.4 \mathrm{~cm}, 3.2 \mathrm{~cm}$, and $3.7 \mathrm{~cm}$ heights (Fig. 2A). A hole at the center of the spacers (Fig. 2B) was made to permit the light pass through, which was measured by a radiometer, establishing the different irradiances used to each photoactivation groups (Fig. 2C).

After light curing, the specimens were stored in an incubator at $37^{\circ} \mathrm{C} \pm 1$ for $24 \mathrm{~h} \pm 1$, in a dark and dry container, before the push-out test. The top and bottom surfaces of restorations were ground using 400-grit sandpapers (Carborundum, Saint-Gobain Abrasivos

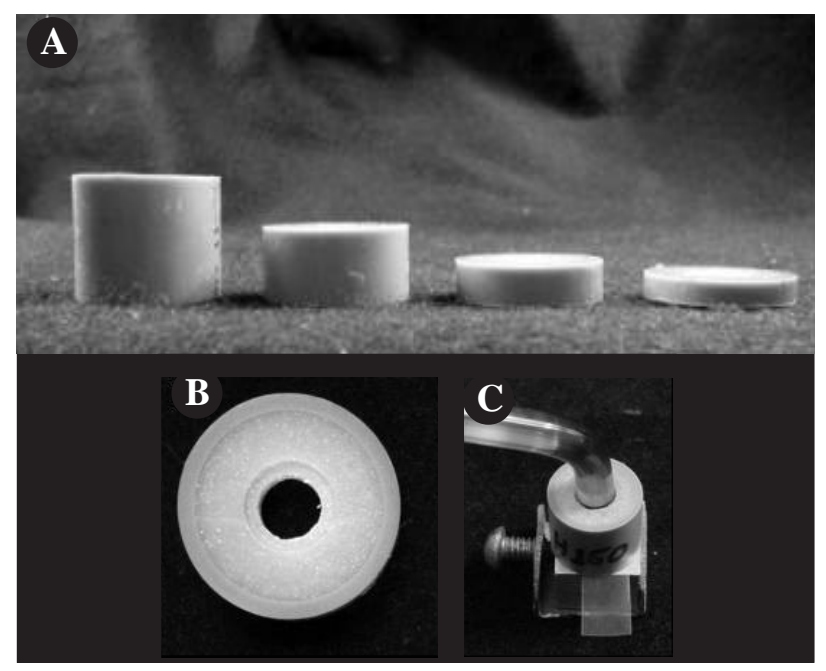

Figure 2. A) acrylic resin spacers of different heights; B) spacer with a central hole for light to pass through; and C) spacer positioned for specimens photoactivation.
Ltda, Cruz de Rebouças, Igaraçu, PE, Brazil) on an automated polisher under water cooling to remove the composite excess, promoting the correct positioning of specimen while testing.

For the push-out test an acrylic resin apparatus containing a central hole was attached to a universal testing machine (Instron model 4411, Instron Ltd, Buckinghamshire, England, UK). A sphere-shaped rod attached to a compression load cell $(500 \mathrm{~N})$ was used to load the composite restorations until failure at a crosshead speed of $0.5 \mathrm{~mm} / \mathrm{min}$. The push-out bond strength was determined by computing the quotient of maximum load $(\mathrm{N})$ and adhesion area (equation for calculation of truncated cones; $\mathrm{mm}^{2}$ ). Data was submitted to one-way ANOVA, followed by Tukey's HSD test at $5 \%$ significance level.

\section{Knoop Hardness Test}

For the Knoop hardness test, 70 specimens were made with a metallic matrix $(5 \mathrm{~mm}$ height $\mathrm{X} 5 \mathrm{~mm}$ diameter) (Fig. 3). The composite resin was bulk inserted. A polyester strip was seated on surface of the specimen and pressed manually to remove composite excesses. Composites were light-cured with halogen lamp, according to the methods suggested for the pushout test: continuous mode $\left(700 \mathrm{~mW} / \mathrm{cm}^{2}\right.$ for $\left.20 \mathrm{~s}\right)$ (CO); soft-start $\left(50 \mathrm{~mW} / \mathrm{cm}^{2}\right.$ for $5 \mathrm{~s}$, followed by 700 $\mathrm{mW} / \mathrm{cm}^{2}$ for $\left.15 \mathrm{~s}\right)(\mathrm{SS} 1)$; soft-start $\left(100 \mathrm{~mW} / \mathrm{cm}^{2}\right.$ for $5 \mathrm{~s}$, followed by $700 \mathrm{~mW} / \mathrm{cm}^{2}$ for $15 \mathrm{~s}$ ) (SS2); softstart $\left(150 \mathrm{~mW} / \mathrm{cm}^{2}\right.$ for $5 \mathrm{~s}$, followed by $700 \mathrm{~mW} / \mathrm{cm}^{2}$ for $15 \mathrm{~s})(\mathrm{SS} 3)$; soft-start $\left(200 \mathrm{~mW} / \mathrm{cm}^{2}\right.$ for $5 \mathrm{~s}$, followed by $700 \mathrm{~mW} / \mathrm{cm}^{2}$ for $15 \mathrm{~s}$ ) (SS4); soft-start

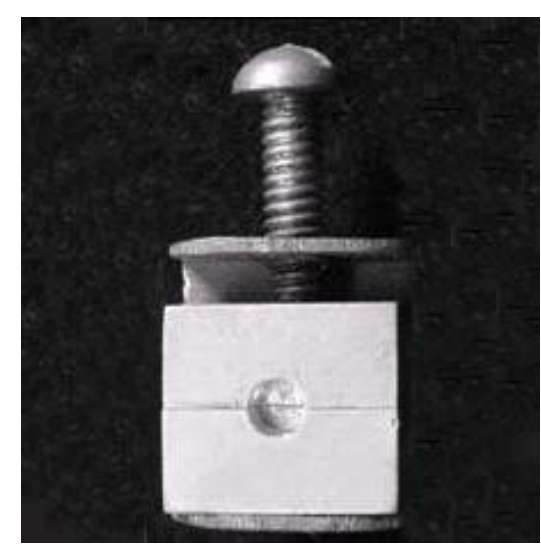

Figure 3. Matrix used for the Knoop hardness test. 
( $250 \mathrm{~mW} / \mathrm{cm}^{2}$ for $5 \mathrm{~s}$, followed by $700 \mathrm{~mW} / \mathrm{cm}^{2}$ for 15 s) (SS5); soft-start $\left(300 \mathrm{~mW} / \mathrm{cm}^{2}\right.$ for $5 \mathrm{~s}$, followed by $700 \mathrm{~mW} / \mathrm{cm}^{2}$ for $15 \mathrm{~s}$ ) (SS6). For reduced irradiances, the tip of the curing units was moved away from the composite surface. To standardize the photoactivation distance, acrylic resin (JET; Artigos Odontológicos Clássico) spacers were interposed between the composite surface and the tip of the light curing units.

After light curing, the specimens were stored in incubator at $37^{\circ} \mathrm{C} \pm 1$ for $24 \mathrm{~h} \pm 1$, in a dark and dry container. Elapsed $24 \mathrm{~h}$, the specimens were embedded in polystyrene resin for grinding and polishing. After curing of the polystyrene resin, the specimens were wet ground and polished using 320-, 400-, 600- and 1200grit sandpapers (Carborundum, Saint-Gobain Abrasivos Ltda.) on an automated polisher. The specimens were dried and submitted to Knoop hardness measurements

Table 1. Push-out bond strength means and standard deviation for resin composite Z250 photo-activated using different methods.

\begin{tabular}{lcc}
\hline Groups & Irradiance $\left(\mathrm{mW} / \mathrm{cm}^{2}\right)$ & Bond strength (MPa) \\
\hline SS1 & $50+700$ & $6.07(0.83) \mathrm{ab}$ \\
SS2 & $100+700$ & $5.97(0.73) \mathrm{ab}$ \\
SS3 & $150+700$ & $7.08(1.34) \mathrm{a}$ \\
SS4 & $200+700$ & $5.91(0.54) \mathrm{ab}$ \\
SS5 & $250+700$ & $6.22(1.12) \mathrm{ab}$ \\
SS6 & $300+700$ & $6.17(1.51) \mathrm{ab}$ \\
CO & 700 & $5.22(0.78) \mathrm{b}$ \\
\hline
\end{tabular}

Different letters indicate statistically significant difference at $5 \%$. in a hardness tester (HMV 2, Shimadzu, Tokyo, Japan) with load of $50 \mathrm{~g}$ for $15 \mathrm{~s}$. For each specimen, 5 readings were taken in different depths (top and 1, 2, 3, 4 and $5 \mathrm{~mm}$ ) and the average was calculated.

Data was submitted to two-way ANOVA (photoactivation mode $\mathrm{x}$ depth) and Tukey's test at the $5 \%$ significance level.

\section{RESULTS}

\section{Push-out Bond Strength}

Table 1 displays the means (SD) for bond strength results. The SS3 group had significantly higher bond strength than CO groups. There were no statistically significant differences among the different soft-start methods. There were no significant differences among groups SS1, SS2, SS4, SS5, SS6 and CO.

\section{Knoop Hardness Test}

Table 2 displays the means (SD) for Knoop hardness. There were no significant differences for Knoop hardness from top up to $4 \mathrm{~mm}$ depth between soft-start method and control group. At $5 \mathrm{~mm}$, group SS4 presented statistically significant higher Knoop hardness means than groups SS2 and SS3 $(\mathrm{p}<0.05)$.

Comparisons among depths (Table 2) show that at $2 \mathrm{~mm}$ depth, Knoop hardness of groups SS1, SS2, SS5 and SS6 was statistically significant lower than that of top surface. Knoop hardness for all groups at $3 \mathrm{~mm}$ depth was significantly lower than that of top surface.

Table 2. Knoop hardness means and standard deviation for Z250 composite resin photoactivated using different methods.

\begin{tabular}{|c|c|c|c|c|c|c|c|}
\hline \multirow[t]{2}{*}{ Group } & \multirow{2}{*}{$\begin{array}{l}\text { Irradiance } \\
\left(\mathrm{mW} / \mathrm{cm}^{2}\right)\end{array}$} & \multicolumn{6}{|c|}{ Knoop Hardness Means (KHN) } \\
\hline & & Top & $1 \mathrm{~mm}$ & $2 \mathrm{~mm}$ & $3 \mathrm{~mm}$ & $4 \mathrm{~mm}$ & $5 \mathrm{~mm}$ \\
\hline SS1 & $50+700$ & $58.32(4.85) \mathrm{a}, \mathrm{A}$ & $54.52(4.97) \mathrm{a}, \mathrm{AB}$ & 51.35 (3.69)a,B & $49.46(3.80) \mathrm{a}, \mathrm{B}$ & $43.54(3.54) \mathrm{a}, \mathrm{C}$ & 29.07 (5.75)abc, D \\
\hline SS2 & $100+700$ & 59.40 (3.77)a,A & $56.62(2.04) \mathrm{a}, \mathrm{AB}$ & $53.45(2.01) \mathrm{a}, \mathrm{B}$ & $51.40(1.25) \mathrm{a}, \mathrm{B}$ & $43.84(2.20) \mathrm{a}, \mathrm{C}$ & $23.20(3.32) \mathrm{c}, \mathrm{D}$ \\
\hline SS3 & $150+700$ & $60.36(5.60) \mathrm{a}, \mathrm{A}$ & $58.82(1.64) \mathrm{a}, \mathrm{A}$ & $56.08(1.42) \mathrm{a}, \mathrm{AB}$ & $51.64(0.47) \mathrm{a}, \mathrm{BC}$ & $45.92(2.41) \mathrm{a}, \mathrm{C}$ & $26.60(5.64) b c, D$ \\
\hline SS4 & $200+700$ & 58.37 (3.92)a,A & $55.55(4.94) \mathrm{a}, \mathrm{AB}$ & $55.52(2.69) \mathrm{a}, \mathrm{AB}$ & $52.36(1.98) \mathrm{a}, \mathrm{BC}$ & 48.68 (3.04)a,C & 33.07 (2.74)a,D \\
\hline SS5 & $250+700$ & $63.15(2.36) \mathrm{a}, \mathrm{A}$ & $60.17(1.36) \mathrm{a}, \mathrm{AB}$ & $56.67(1.82) \mathrm{a}, \mathrm{BC}$ & $53.55(1.77) \mathrm{a}, \mathrm{CD}$ & $49.61(1.92) \mathrm{a}, \mathrm{D}$ & 28.47 (2.03)abc,E \\
\hline SS6 & $300+700$ & $61.14(3.14) \mathrm{a}, \mathrm{A}$ & $57.54(2.61) \mathrm{a}, \mathrm{AB}$ & $55.02(1.29) \mathrm{a}, \mathrm{BC}$ & $49.49(1.01) \mathrm{a}, \mathrm{CD}$ & $44.33(1.88) \mathrm{a}, \mathrm{D}$ & $31.60(2.26) \mathrm{ab}, \mathrm{E}$ \\
\hline $\mathrm{CO}$ & 700 & $62.10(5.54) \mathrm{a}, \mathrm{A}$ & 59.45 (4.60)a,A & $56.46(3.66) \mathrm{a}, \mathrm{AB}$ & $53.00(2.76) \mathrm{a}, \mathrm{BC}$ & 49.38 (2.40)a,C & 28.27 (3.47)abc,D \\
\hline
\end{tabular}

Different lowercase letters in the columns and uppercase letters in the rows indicate statistically significant difference at $5 \%$. 


\section{DISCUSSION}

The test design for this study was a push-out model. Extrusion testing in dentistry was first described by Roydhouse in 1970 (11). This author proposed pushing out dental material cylinders from tooth discs. Previous studies using a conical version of the push-out design demonstrated the different bonding properties of direct and indirect restorations with highly reproducible measurements (12). In addition, the cavity-like configuration of the bonding area allows the determination of both composite bond strength and marginal adaptation on the same specimen (12). Independently of the photoactivation method applied, the DC must be as high as possible, ensuring that the material achieves the best properties. It has been demonstrated a good correlation between DC and hardness of composites and, hence, hardness is useful as an indicator of DC (5).

Composite polymerization is a complex phenomenon that involves innumerous factors. The magnitude of stress development depends on the volume fraction of fillers, filler geometry, ratio of modulus between polymer and particle, adhesion between polymer and particle, inherent shrinkage of the particle, and degree of polymer cure. The shrinkage stress has great importance to longevity and success composites, and depends on the polymerization rate, composition of polymeric matrix, specimen geometry, filler volume fraction, photoinitiator concentration, and curing method. The rate of polymerization is influenced by the photoinitiator concentration, monomer reactivity, molecular weight of monomer, leading to different viscosities and mobility (13). Moreover, characteristics related to light curing unit, such as energy density and spectral flow, also alter final material properties (3). Energy density is the product of irradiance and the duration of light exposure, whilst spectral flow represents the optical power output from the light-curing unit, in $\mathrm{mW}$, at each given wavelength (14). In a photoactivated composite, DC depends on the total energy density, at the correct wavelength, supplied to the photoinitiator. Reduction of this initial speed can be obtained by using low irradiance units that produce few free radicals (15). This lower speed gives the composite more time for molecular rearrangement, reducing the stress caused by polymerization shrinkage (16).

The soft-start method described by Uno and Asmussen (17) uses the premise that a short pulse of light allows the relief of stresses prior to inducing additional stresses during the continuing polymerization (18). In this work, the amount of photons supplied to composite within the same exposure time was changed. If the polymerization reaction depends on the generation of free radicals, the speed reaction would be changed for different irradiances during photoactivation. The results showed the soft-start method using $150 \mathrm{~mW} /$ $\mathrm{cm}^{2}$ initial irradiance (SS3) produced significantly higher bond strength than the control group (CO). The low irradiance during the photoactivation cycle makes the polymerization reaction to proceed slowly, allowing the relief of shrinkage stresses and decreasing the stress at tooth-restorative material interface. In addition, SS3 presented Knoop hardness means similar to CO group ( $>0.05$ ). This means that, in those specimens, less stress occurred at bond interface, whilst the DC was maintained. According to Sakaguchi et al. (18), the maximum contraction force rate occurs within the first $10 \mathrm{~s}$ of photoactivation. The contraction force can lead to rupture at the bond interface, promoting lower bond strength. When soft-start method is used, the initial irradiance has a great importance for bond strength. When low irradiance was used, SS1 and SS2 groups, bond strength was similar to $\mathrm{CO}$ group. It was expected that by using low-irradiance photoactivation, the bond strength would be increased. However, it seemed that in those specimens the energy density of the initial photoactivation was not enough to effectively initiate the polymerization reaction. The reaction only became effective when the second high irradiance exposure occurred. Thus, the reaction occurred under high intensity similar to $\mathrm{CO}$, leading to gap formation and lower bond strength (19). This may be seen in the Knoop hardness test, in which SS1 and SS2 groups had Knoop hardness means similar to those of CO.

There were no statistical differences among SS4, SS5, SS6 and CO for bond strength. The speed reaction has been decreased to give the composite more time for molecular rearrangement, reducing the stress caused by polymerization shrinkage (16). Maybe, the high energy density during the first curing cycle for SS4, SS5, and SS6 produced high conversion of double bonds, leading to high polymerization shrinkage and contraction force. This can be seen in the similar bond strength results to CO. Regardless of the light modulation method, it has been recommended that energy densities similar those supplied by conventional 
photoactivation (continuous mode) be used. This is recommended because previous studies reported that the degree of conversion depends on the energy density that is supplied to the composite and the photoactivation method (20). Koran and Kurschner (7) found that the increase in energy density led to an increase in the hardness values until photoactivation with $17 \mathrm{~J} / \mathrm{cm}^{2}$, after which there was no significant alteration in hardness values. However, the ideal energy density for photoactivation is composite dependent. In this study the energy density variations $\left(10.95-14.00 \mathrm{~J} / \mathrm{cm}^{2}\right)$ have no effect on DC, seen on Knoop hardness values.

In conclusion, the initial irradiance variations for the soft-start photoactivation method influence on bond strength, but do not have any effects on Knoop hardness values of Z250 composite resin. The best alternative for the traditional mode (continuous mode) is the soft-start mode with $150 \mathrm{~mW} / \mathrm{cm}^{2}$ initial pulse.

\section{RESUMO}

Este estudo avaliou a resistência de união (push-out) e a dureza Knoop do compósito Z250, fotoativado por luz de lâmpada halógena XL2500, com diferentes modos: Contínuo (700 mW/ $\left.\mathrm{cm}^{2} / 20 \mathrm{~s}\right)(\mathrm{CO})$; Soft-start $\left(50 \mathrm{~mW} / \mathrm{cm}^{2} / 5 \mathrm{~s}+700 \mathrm{~mW} / \mathrm{cm}^{2} / 15 \mathrm{~s}\right)$ (SS1), $\left(100 \mathrm{~mW} / \mathrm{cm}^{2} / 5 \mathrm{~s}+700 \mathrm{~mW} / \mathrm{cm}^{2} / 15 \mathrm{~s}\right)(\mathrm{SS} 2),(150 \mathrm{~mW} /$ $\left.\mathrm{cm}^{2} / 5 \mathrm{~s}+700 \mathrm{~mW} / \mathrm{cm}^{2} / 15 \mathrm{~s}\right)(\mathrm{SS} 3),\left(200 \mathrm{~mW} / \mathrm{cm}^{2} / 5 \mathrm{~s}+700 \mathrm{~mW} /\right.$ $\left.\mathrm{cm}^{2} / 15 \mathrm{~s}\right)(\mathrm{SS} 4),\left(250 \mathrm{~mW} / \mathrm{cm}^{2} / 5 \mathrm{~s}+700 \mathrm{~mW} / \mathrm{cm}^{2} / 15 \mathrm{~s}\right)(\mathrm{SS} 5)$, $\left(300 \mathrm{~mW} / \mathrm{cm}^{2} / 5 \mathrm{~s}+700 \mathrm{~mW} / \mathrm{cm}^{2} / 15 \mathrm{~s}\right)(\mathrm{SS} 6)$. Para o ensaio de resistência de união, os espécimes foram testados em máquina de ensaio universal com velocidade de $0,5 \mathrm{~mm} / \mathrm{min}$. Para o teste de dureza, os espécimes foram polidos para a realização das leituras de dureza, realizadas com carga de $50 \mathrm{~g}$ por $15 \mathrm{~s}$. Os dados foram submetidos a ANOVA e ao teste de Tukey $(\alpha=5 \%)$. Os resultados de resistência da união mostraram que o grupo SS3 apresentou maior resistência da união quando comparado ao grupo CO. Não houve diferença entre os demais grupos testados. O teste de dureza Knoop mostrou que não houve diferença entre os grupos até $4 \mathrm{~mm}$ de profundidade.

\section{REFERENCES}

1. Peutzfeldt A. Resin composites in dentistry: the monomer systems. Eur J Oral Sci 1997;105:97-116.

2. Walls AW, McCabe JF, Murray JJ. The polymerization contraction of visible-light activated composite resins. J Dent 1988;16:177-181.

3. Correr AB, Sinhoreti MA, Correr Sobrinho L, Tango RN, Schneider LF, Consani S. Effect of the increase of energy density on knoop hardness of dental composites light-cured by conventional QTH, LED and xenon plasma arc. Braz Dent
J 2005; 16:218-224.

4. Filipov IA, Vladimirov SB. Residual monomer in a composite resin after light-curing with different sources, light intensities and spectra of radiation. Braz Dent J 2006;17:34-38.

5. Rueggeberg FA, Craig RG. Correlation of parameters used to estimate monomer conversion in a light-cured composite. J Dent Res 1988;67:932-937.

6. Feilzer AJ, Dooren LH, de Gee AJ, Davidson CL. Influence of light intensity on polymerization shrinkage and integrity of restoration-cavity interface. Eur J Oral Sci 1995;103:322326.

7. Koran P, Kurschner R. Effect of sequential versus continuous irradiation of a light-cured resin composite on shrinkage, viscosity, adhesion, and degree of polymerization. Am J Dent 1998;11:17-22.

8. Sakaguchi RL, Berge HX. Reduced light energy density decreases post-gel contraction while maintaining degree of conversion in composites. J Dent 1998;26:695-700.

9. Kinomoto Y, Torii M, Takeshige F, Ebisu S. Comparison of polymerization contraction stresses between self- and lightcuring composites. J Dent 1999;27:383-389.

10. Obici AC, Sinhoreti MA, Correr Sobrinho L, Goes MF, Consani, S. Evaluation of depth of cure and Knoop hardness in a dental composite photo-activated using different methods. Braz Dent J 2004;15:199-203.

11. Roydhouse RH. Punch-shear test for dental purposes. J Dent Res 1970;49:131-136.

12. Frankenberger R, Sindel J, Kramer N, Petschelt A. Dentin bond strength and marginal adaptation: direct composite resins vs ceramic inlays. Oper Dent 1999;24:147-155.

13. Asmussen E, Peutzfeldt A. Influence of composition on rate of polymerization contraction of light-curing resin composites. Acta Odontol Scand 2002;60:146-150.

14. Stahl F, Ashworth SH, Jandt KD, Mills RW. Light-emitting diode (LED) polymerisation of dental composites: flexural properties and polymerisation potential. Biomaterials 2000;21:1379-1385.

15. Asmussen E, Peutzfeldt A. Influence of pulse-delay curing on softening of polymer structures. J Dent Res 2001;80:15701573.

16. Obici AC, Sinhoreti MA, de Goes MF, Consani S, Sobrinho LC. Effect of the photo-activation method on polymerization shrinkage of restorative composites. Oper Dent 2002;27:192198.

17. Uno S, Asmussen E. Marginal adaptation of a restorative resin polymerized at reduced rate. Scand J Dent Res 1991;99:440444.

18. Sakaguchi RL, Wiltbank BD, Murchison CF. Contraction force rate of polymer composites is linearly correlated with irradiance. Dent Mater 2004;20:402-407.

19. Yap AU, Soh MS, Siow KS. Post-gel shrinkage with pulse activation and soft-start polymerization. Oper Dent 2002;27:81-87.

20. Friedman J, Hassan R. Comparison study of visible curing lights and hardness of light-cured restorative materials. J Prosthet Dent 1984;52:504-506. 